http://sciforum.net/conference/ecm-1

Article

\title{
Magnetic Hybrid Iron Oxide-Based Composite Nanocatalyst for the Synthesis of Polyhydroquinolines under Solvent-Free Conditions at Room Temperature
}

\author{
Ali Maleki , Negar Hamidi and Saied Maleki \\ Department of Chemistry, Iran University of Science and Technology, Tehran 16846-13114, Iran \\ * Author to whom correspondence should be addressed; E-mail: maleki@iust.ac.ir (A. Maleki); Tel.: \\ +98-21-77240640-50; Fax: +98-21-73021584.
}

Received: 15 April 2014 / Accepted: 15 May 2014 /Published: 26 May 2014

\begin{abstract}
A green and efficient multicomponent one-pot synthesis of Hantzsch polyhydroquinoline was achieved by the condensation of aldehydes, dimedone, ethyl acetoacetate and ammonium acetate at room temperature under solvent-free conditions by using magnetic hybrid iron oxide as a recyclable nanocatalyst. Compared to the classical reactions, this method consistently has the advantages of short reaction times, little catalyst loading, high yields, easy magnetic separation and reusability of the catalyst.
\end{abstract}

Keywords: Magnetic nanoparticles; $\mathrm{Fe}_{3} \mathrm{O}_{4}$; Nanocomposite; Heterogeneous catalysts; Polyhydroquinoline; Multicomponent reaction.

\section{Introduction}

Multicomponent reactions (MCRs) are one-pot processes in which three or more accessible components react to form a single product that incorporates essentially most or all atoms of the reactants used [1]. One-pot multicomponent strategies grant remarkable advantages over usual bimolecular reactions owing to their convergence, atom-economy, operational simplicity, structural diversity and shortness of the synthetic pathway [2]. MCRs have recently gained a new dimension in the field of designing methods to produce elaborate libraries of biologically active compounds. 
The 1,4-dihydropyridine (1,4-DHP) core is found in a range of compounds exhibiting abroad spectrum of biological activities [3-4]. Some of the representative compounds of this class possess antimicrobial, anti tubercular, insecticidal, and neuroprotectant activities. In particular 4-aryl-1, 4-DHPs are well known as calcium-channel blockers and have emerged as one of the most important classes of drug for the treatment of cardiovascular diseases.

Recently, 1,4-DHPs have been used as organ catalysts for asymmetric reactions such as hydrogenation of quinolones in the synthesis of alkaloids asymmetric reductive amination of aldehydes and hydrogenation of $\alpha, \beta$-unsaturated aldehydes and ketones. Polyhydroquinolines (PHQs) are a class of fused 1, 4-DHPs that have received less attention than other fused 1,4-DHPs, and comparatively few methods for their preparation have been reported. (PHQs) are generally synthesized by an unsymmetrical Hantzsch reaction which involves the one-pot, four-component condenseition of dimedone, aldehyde, ethylacetoacetate and ammonium acetate.

At the present time, simple separation and recycling of the catalysts are fundamental steps in catalytic technology and frequently affect the overall process economy. A possible method is immobilizing catalytically active species in the surface of magnetic nanoparticles which can be separated and recovered from the reaction system by applying an appropriate magnetic field.

In general, in order to prevent direct contact between magnetite nanoparticles and also provide a chemically inert surface for modification of magnetite nanoparticles, coating of the surface with silica shell is necessary. Silica surface can be easily functionalized with various organic groups for desired purposes such as applications as adsorbent, catalysis support, and enzyme immobilization.Therefore, several alternate and more efficient methods have been developed for the synthesis of dihydropyridine and poly hydroquinone derivatives such as using conventional heating [5], $\mathrm{FeF}_{3}$ [6], and $\mathrm{Yb}(\mathrm{OTF})_{3}$ [78].

In this work, a magnetic dichromate hybrid with triphenylphosphine surface modified iron oxide nanoparticles $\mathrm{Fe}_{3} \mathrm{O}_{4} @ \mathrm{SiO}_{2} @ \mathrm{PPh}_{3} @\left[\mathrm{Cr}_{2} \mathrm{O}_{7}\right]$ (FSPC) [8] as a recoverable and efficient nanocomposite catalyst is prepared and applied for the synthesis of polyhydroquinolines under solvent-free conditions at room temperature. This research can be classified as a green approach for efficient and rapid synthesis of biologically active substituted polyhydroquinoline derivatives by using a recyclable nanocatalyst under mild reaction conditions. Polyhydroquinoline derivatives $\mathbf{5}$ are synthesised via a multicomponent reaction starting from various aldehydes $\mathbf{1}$, dimedone $\mathbf{2}$, etylaceto acetate $\mathbf{3}$ and ammonium acetate $\mathbf{4}$ (Scheme 1).

Scheme 1. Synthesis of polyhydroquinolines.

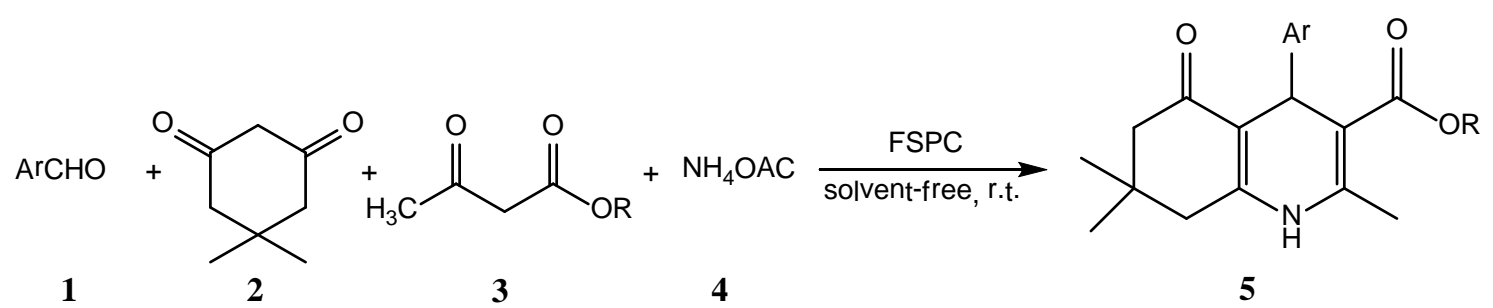




\section{Results and Discussion}

The dichromate magnetic nanoparticles were investigated as a catalyst in the synthesis of polyhydroquinoline derivatives. Condensation of benzaldehyde derivatives, dimedone, ethylacetoacetate, and ammonium acetate in the presence of FSPC under solvent-free conditions at room temperature was performed and afforded products in 80-95\% yield. Such reactions occur with a wide range of aromatic aldehydes carrying either electron-donating or electron withdrawing substituent in the ortho, meta, and para positions (Table 1).

All product were characterized by their FT-IR spectral data and a comparison of their melting point with those of authentic samples.

Table 1 FSPC-catalyzed synthesis of polyhydroquinoline derivatives $\mathbf{5 a - f .}{ }^{\text {a }}$

\begin{tabular}{|c|c|c|c|c|c|}
\hline \multirow{2}{*}{$\mathrm{Ar}$} & \multirow{2}{*}{ Product } & \multirow{2}{*}{ Time (min) } & \multirow{2}{*}{ Yield $^{\mathrm{b}}(\%)$} & \multicolumn{2}{|c|}{$\mathrm{Mp}\left({ }^{\circ} \mathrm{C}\right)$} \\
\hline & & & & Found & Reported \\
\hline $4-\mathrm{MeOC}_{6} \mathrm{H}_{4}$ & $5 a$ & 10 & 90 & 260 & $258-260[9]$ \\
\hline 4- $\mathrm{MeC}_{6} \mathrm{H}_{4}$ & $5 b$ & 11 & 91 & $255-256$ & 258-260[10] \\
\hline $4-\mathrm{ClC}_{6} \mathrm{H}_{4}$ & $5 c$ & 20 & 95 & 244-245 & 241-243[11] \\
\hline $2-\mathrm{ClC}_{6} \mathrm{H}_{4}$ & $5 d$ & 20 & 87 & 201-202 & 202-205[12] \\
\hline $4-\mathrm{OHC}_{6} \mathrm{H}_{4}$ & $5 e$ & 15 & 82 & $235-236$ & 232-234[13] \\
\hline $4-\mathrm{O}_{2} \mathrm{NC}_{6} \mathrm{H}_{4}$ & $5 f$ & 25 & 80 & 240 & $240-242[13]$ \\
\hline
\end{tabular}

${ }^{\text {a }}$ Reaction conditions an aldehyde 1 (1 mmol). dimedone 2 (1 mmol), ethyl acetoacetate 3 (1 mmol), ammonium acetate 4 ( $1 \mathrm{mmol})$, FSPC (0.01 g), room temperature, solvent-free.

${ }^{\mathrm{b}}$ Isolated yields.

To investigate the effects of solvent, the condensation reaction of 4-cholorobenzaldehyde, dimedone, ethylacetoacetate, and ammonium acetate in $\mathrm{H}_{2} \mathrm{O}, \mathrm{CH}_{3} \mathrm{CN}$ and solvent-free system at room temperature using $0.01 \mathrm{~g}$ FSPC as the catalyst was carried out. About 40, 45 and 95\% of the expected product 5c (Table 1) was obtained in $\mathrm{H}_{2} \mathrm{O}, \mathrm{CH}_{3} \mathrm{CN}$, and under solvent-free conditions, respectively (Table 2). Obviously, the solvent-free system was much better than polar solvents; because they were performed in short reaction times in excellent yields. The model reaction was carried out without any catalyst, but the product formation was trace. Therefore, the catalyst plays an important role in the reaction in terms of rate and yields of Hantzsch polyhydroquinoline derivatives. 
Table 2 Effect of amount of catalyst, type of solvent and temperature on the model reaction.

\begin{tabular}{cccccc}
\hline Entry & Catalyst(g) & Solvent & Temperature $\left({ }^{\circ} \mathrm{C}\right)$ & Time (min) & Yield ${ }^{\mathrm{a}}(\%)$ \\
\hline 1 & - & - & 120 & 120 & trace \\
2 & 0.002 & - & r.t. & 60 & 58 \\
3 & 0.005 & - & r.t. & 45 & 80 \\
4 & 0.01 & - & r.t. & 20 & 95 \\
5 & 0.01 & $\mathrm{H}_{2} \mathrm{O}$ & r.t. & 70 & 45 \\
6 & 0.01 & $\mathrm{CH}_{3} \mathrm{CN}$ & r.t. & 90 & 40 \\
\hline
\end{tabular}

${ }^{\mathrm{a}}$ Isolated yields.

A comparison of the efficiency and catalytic activity of the dichromate magnetic nanocatalyst with several previous methods is presented in Table 3. The results indicate that this method is better than other existing methods because it has shorter reaction times, high yields, and easy workup.

Table 3. Comparison of catalytic activity.

\begin{tabular}{ccccccc}
\hline Entry & Catalyst & Solvent & Time (min) & Temp. $\left({ }^{\circ} \mathrm{C}\right)$ & Yield $^{\text {a }}(\%)$ & Ref. \\
\hline 1 & $\mathrm{Mg} \mathrm{Al} 2 \mathrm{HT}$ & $\mathrm{CH}_{3} \mathrm{CN}$ & 390 & r.t. & $32-75$ & {$[14]$} \\
2 & Cellulose sulfuric acid & - & $120-300$ & 100 & $78-92$ & {$[15]$} \\
3 & $\mathrm{NaHSO}_{4}-\mathrm{SiO}_{2}$ & $\mathrm{CH}_{3} \mathrm{CN}$ & $300-480$ & r.t. & $75-90$ & {$[16]$} \\
4 & $\mathrm{Fe}_{3} \mathrm{O}_{4} @ \mathrm{SiO}_{2}$ & $\mathrm{C}_{2} \mathrm{H}_{5} \mathrm{OH}$ & 240 & r.t. & 60 & This work \\
5 & $\mathrm{Fe}_{3} \mathrm{O}_{4} @ \mathrm{SiO}_{2} @ \mathrm{PPh}_{3}$ & $\mathrm{C}_{2} \mathrm{H}_{5} \mathrm{OH}$ & 180 & r.t. & 70 & This work \\
6 & $\mathrm{PPh}_{3}$ & $\mathrm{C}_{2} \mathrm{H}_{5} \mathrm{OH}$ & $120-300$ & reflex & $72-95$ & {$[17]$} \\
7 & $\mathrm{FSPC}$ & - & $10-25$ & r.t. & $85-95$ & This work
\end{tabular}

${ }^{\mathrm{a}}$ Isolated yields. 


\section{Experimental Section}

\subsection{Materials and methods}

All chemicals were purchased from Merck, Fluka and Sigma-Aldrich companies and were used without further purification. All reactions and the purity of polyhydroquinoline derivatives were monitored by thin-layer chromatography (TLC) using aluminum plates coated with silica gel F254 plates (Merck) using ethyl acetate and $n$-hexane as eluents. The spots were detected either under UV light or by placing in an iodine chamber. Melting points were determined in open capillaries using an Electro thermal 9100 instrument. Fourier transform infrared (FT-IR) spectra were recorded using Perkine-Elmer Spectrum RXI FT-IR spectrometer; using pellets of the nanomaterials diluted with $\mathrm{KBr}$.

\subsection{Synthesis of Hantzsch polyhydroquinoline derivatives}

To a mixture of aromatic aldehyde ( $1 \mathrm{mmol})$, dimedone (1 mmol), ethyl acetoacetate ( $1 \mathrm{mmol})$, and ammonium acetate $(1.5 \mathrm{mmol})$ in a $10 \mathrm{ml}$ round bottom flask $0.01 \mathrm{~g}$ of FSPC was added. The mixture was homogenized and stirred at room temperature for 15-30 min, the progress of the reaction was monitored by thin layered chromatography (TLC) (Eluent:EtOAc:n-hexane). After completion of the reaction, $5 \mathrm{ml}$ ethyl acetate was added and the catalyst was removed from the solution using a magnet. Then the crude products were recrystallized in ethyl acetate-n-hexane. The products were characterized by FT-IR and melting point. The yields of pure products were 85-95\%. Then recycled catalyst was used for subsequent runs (five times) under the same conditions without significant loss of its catalytic activity.

\subsection{Spectral data for the synthesis of polyhydroquinoline derivatives}

Ethyl 4-(4-chlorophenyl)-2,7,7-trimethyl-5-oxo-1,4,5,6,7,8-hexahydroquinoline-3-carboxylate (Table 1, 5c): Yield: 95\%; Mp 244- $245^{\circ} \mathrm{C}$, IR $\left(\mathrm{KBr}, \mathrm{cm}^{-1}\right)$ 3270, 3195, 3070, 2945, 1670, 1604, 1475, 1367, 1227, 1105, 875

\section{Conclusions}

We have reported that four-component Hantzsch condensation reaction that can effectively be performed with a magnetic dichromate hybrid with triphenylphosphine surface modified iron oxide nanoparticles for production of polyhydroquinoline derivatives. The advantages of this method are its facile conditions, easy isolation of the products with excellent purity, and without using of column chromatography. It is a green system for the synthesis of polyhydroquinoline without any solvent, little catalyst loading, high yield, environmentally benign, and waste-free chemical process.

\section{Acknowledgments}

The authors gratefully acknowledge the partial support from the Research Council of the Iran University of Science and Technology. 


\section{Conflicts of Interest}

The authors declare no conflict of interest.

\section{References and Notes}

1. Zhu, J.; Bienaymé, H. Multicomponent reactions. Wiley-VCH, Weinheim, 2005.

2. Weber, L. Current awareness on comparative and functional genomics. Drug Disc. Today 2002, 7 , 143-147.

3. Carosati, E.; Ioan, P.; Micucci, M.; Broccatelli, F.; Cruciani, G.; Zhorov, B. S.; Chiarini, A.; Budriesi, R. 1,4-Dihydropyridine scaffold in medicinal chemistry, the story so far and perspectives (part 2): Action in other targets and antitargets. Curr. Med. Chem. 2012, 19, 4306-4323.

4. Guengerich, F. P.; Martin, M. V.; Beaune, P. H.; Kremers, P.; Wolff, T.; Waxman, D. J. Characterization of rat and human liver microsomal cytochrome P-450 forms involved in nifedipine oxidation, a prototype for genetic polymorphism in oxidative drug metabolism. $J$. Biol. Chem. 1986, 261, 5051-5060.

5. Suáreza, M.; Ochoa, E.; Verdeciaa, Y.; Pitaa, B.; Morána, L.; Martín, N.; Quinteirob, M.; Seoane, C.; Soto, J.; Novoa, H.; Blaton, N.; Peters, O. M. A joint experimental and theoretical structural study of novel substituted 2,5-dioxo-1,2,3,4,5,6,7,8-octahydroquinolines. Tetrahedron 1999, 55, 875-884.

6. Surasani, R.; Kalita, D.; Rao, A.V.D.; Yarbagi, K.; Chandrasekhar, K.B. FeF 3 as a novel catalyst for the synthesis of polyhydroquinoline derivatives via unsymmetrical Hantzsch reaction. Fluorine Chem. 2012, 135, 91-96.

7. Wang, L.M.; Sheng, J.; Zhang, L.; Han, J.W.; Fan, Z.Y.; Tian, H.; Qian, C.T. Facile Yb(OTf) 3 promoted one-pot synthesis of polyhydroquinoline derivatives through Hantzsch reaction. Tetrahedron 2005, 61, 1539-1543.

8. Rahimi, R.; Maleki, A.; Maleki, S.; Morsali, A.; Rahimi, M.J. Synthesis and characterization of magnetic dichromate hybrid nanomaterials with triphenylphosphine surface modified iron oxide nanoparticles $\left(\mathrm{Fe}_{3} \mathrm{O}_{4} @ \mathrm{SiO}_{2} @ \mathrm{PPh}_{3} @ \mathrm{Cr}_{2} \mathrm{O}_{7}{ }^{2-}\right)$. Solid State Sci. 2014, 28, 9-13.

9. Safari, J.; Banitaba, S.; Khalili, S.D. Cobalt nanoparticles promoted highly efficient one pot fourcomponent synthesis of 1,4-dihydropyridines under solvent-free conditions. Chin. J. Catal. 2011, 32, 1850-1855.

10. Tafer, R.; Boulcina, R.; Carboni, B.; Debache, A. Cd(NO3)2.4H2O Catalyzed one-pot synthesis of 1,4-dihydropyridine and polyhydroquinoline derivatives through the Hantzsch multicomponent condensation . J. Chin. Chem. Soc. 2012, 59, 1555-1560.

11. Maleki, B.; Tayebee, R.; Sepehr, Z.; Kermanian, M. A. Novel, heterogeneous and recyclable polymeric catalyst for the one-Pot synthesis of polyhydroquinoline and 1,8dioxohexahydroacridine derivatives under solvent-free conditions. Acta. Chim. Slov. 2012, 59, 814-823.

12. Mobinikhaledi, A.; Foroughifar, N.; Fard, M.A.B.; Moghanian, H.; Ebrahimi, S.; Kalhor, M. Efficient one-pot synthesis of polyhydroquinoline derivatives using silica sulfuric acid as a 
heterogeneous and reusable catalyst under conventional heating and energy-saving microwave irradiation. Synth. Commun. 2009, 39, 1166-1174.

13. Heydari, A.; Khaksar, S.; Tajbakhsh, M.; Bijanzadeh, H. R. One-step,synthesis of Hantzsch esters and polyhydroquinoline derivatives in fluoro alcohols. J. Fluorine Chem. 2009, 130, 609-614.

14. Antonyraj, C. A.; Kannan, S. Hantzsch pyridine synthesis using hydrotalcites or hydrotalcite-like materials as solid base catalysts. Appl. Catal. A. 2008, 338,121-129.

15. Murthy, Y. L. N.; Rajack, A.; Ramji, M. T; Babu, J. J.; Praveen, C; Lakshmi, K. A. Design, solvent free synthesis, and antimicrobial evaluation of 1,4 dihydropyridines. Bioorg. Med. Chem. Lett. 2012, 22, 6016-6023.

16. Chari, M. A.; Syamasundar, K. Silica gel/NaHSO4 catalyzed one-pot synthesis of Hantzsch 1,4dihydropyridines at ambient temperature. Catal. Commun. 2005, 6, 624-627.

17. Debache, A.; Ghalem, W.; Boulcina, R.; Belfaitah, A.; Rhouati, S.; Carboni, B. An efficient onestep synthesis of 1,4-dihydropyridines via a triphenylphosphine-catalyzed three-component Hantzsch reaction under mild conditions. Tetrahedron Lett. 2009, 50, 5248-5250.

(C) 2014 by the authors; licensee MDPI, Basel, Switzerland. This article is an open access article distributed under the terms and conditions of the Creative Commons Attribution license (http://creativecommons.org/licenses/by/3.0/). 